\title{
Alfred De Musset, Les Caprices de Marianne - Nouvelles
}

\section{Barbara T. Cooper}

\section{(2) OpenEdition}

10 Journals

\section{Édition électronique}

URL : https://journals.openedition.org/studifrancesi/39663

DOI : 10.4000/studifrancesi.39663

ISSN : 2421-5856

Éditeur

Rosenberg \& Sellier

\section{Édition imprimée}

Date de publication : 1 décembre 2004

Pagination : 397

ISSN : 0039-2944

\section{Référence électronique}

Barbara T. Cooper, «Alfred De Musset, Les Caprices de Marianne - Nouvelles », Studi Francesi [En ligne], 143 (XLVIII | II) | 2004, mis en ligne le 30 novembre 2015, consulté le 19 mai 2021. URL : http:// journals.openedition.org/studifrancesi/39663 ; DOI : https://doi.org/10.4000/studifrancesi.39663

Ce document a été généré automatiquement le 19 mai 2021.

\section{(c) (i) $\ominus$}

Studi Francesi è distribuita con Licenza Creative Commons Attribuzione - Non commerciale - Non opere derivate 4.0 Internazionale. 


\title{
Alfred De Musset, Les Caprices de Marianne - Nouvelles
}

\author{
Barbara T. Cooper
}

\section{RÉFÉRENCE}

ALFRED DE MUSSET, Les Caprices de Marianne, édité par FRANK LESTRINGANT, Paris, Gallimard, 2001 («Folio Théâtre») pp. 174.

ALFRED DE MUSSET, Nouvelles, édité par SYLVAN LEDDA, Jaignes, La Chasse au Snark, 2002, pp. 440.

1 Si Alfred de Musset est aujourd'hui l'auteur le plus joué du théâtre romantique français, il est moins connu pour ses nouvelles. Saluons donc l'heureuse initiative de Sylvan Ledda et de la maison d'édition La Chasse au Snark qui font paraître ces petits textes en prose permettant ainsi une meilleure connaissance de l'œuvre mussétienne. Saluons, également, le travail de Frank Lestringant qui publie en «Folio Théâtre» Les Caprices de Marianne et profite, pour enrichir son analyse de cette pièce, de la connaissance intime de la vie et l'œuvre de Musset qu'il a acquise en rédigeant sa biographie de l'auteur (Flammarion, 1999).

2 En présentant les six nouvelles -Emmeline, Les Deux Maîtresses, Frédéric et Bernerette, Le Fils du Titien, Margot et Croisilles- parues dans la Revue des Deux Mondes entre le 15 août 1837 et le 15 février 1839, Sylvan Ledda note que Musset ne les écrivait qu'afin de satisfaire à des besoins pécuniares. Ces textes ne sont toutefois pas sans intérêt et ont d'importants liens avec la vie et l'œuvre de Musset que Ledda, dans sa préface, ne manque pas d'élucider.

3 Preuves en main, Ledda montre comment certains éléments biographiques et épistolaires, à peine modifés, se fondent dans la fiction. Ainsi, selon lui, les héros de ces récits doivent beaucoup à la personnalité, aux expériences et aux préoccupations de Musset, alors que les personnages féminins rappellent par certains côtés deux des maîtresses de l'auteur -Caroline Jaubert et Aimée d'Alton-Shée. Ledda souligne aussi ce 
qui rapproche ces histoires d'amour non seulement d'autres écrits de Musset -par exemple, les Contes d'Espagne et d'Italie, La Confession d'un enfant du siècle et le Spectacle dans un fauteuil, mais aussi des contes de ses prédécesseurs comme Carmontelle. Il signale également le caractère hybride de ces nouvelles. Elles contiennent des passages en vers, des récits enchâssés et des lettres intercalées, des éléments réalistes ainsi que des touches de merveilleux et des allusions à d'autres formes artistiques (la peinture, la musique, la danse). Elles ont pour cadre la France des XVIII ${ }^{e}$ (Croisilles) et XIX ${ }^{e}$ siècles (Emmeline, Les Deux Maîtresses, Frédéric et Bernerette, Margot) et l'Italie de la Renaissance (Le Fils du Titien).

4 Galanteries, égarements, déchirements sentimentaux, caprices- toutes les variations, tous les périls des histoires d'amour habituels chez Musset figurent dans ces nouvelles qui ne se terminent jamais par la plénitude du bonheur, mais ne sont pas moins marqués par le lyrisme typique de l'auteur. Ledda analyse avec minutie, rigueur et érudition chaque aspect de ces textes avant de conclure: «Aujourd'hui, nous pouvons lire ces récits comme nous écoutons les Valses de Chopin. Un plaisir subtil est assuré» (p. 57). On ne peut que lui donner raison. Ces pages, où les charmes du style et les chagrins d'amour nous font plonger au cœur même de l'univers mussétien, sont à découvrir ou à redécouvrir au plus vite. L'excellente préface et les notes fournies par Sylvan Ledda sont là pour guider le lecteur; elles encadrent le texte sans l'encombrer et offrent matière à la réflexion. On peut certes regretter les quelques coquilles glissées dans ces récits («il se livrait à ses idées, [sic] sombres» p. 124; «Il est temps [...] de rompre avec des habitudes qui ne peuvent que me conduire, [sic] à ma perte» p. 238; «une telle scène, en effet, traitée avec simplicité Par [sic] un véritable artiste» p. 320), mais elles ne constituent pas un véritable obstacle à la lecture. À la fin du volume, on trouvera des éléments de l'histoire du texte et une bibliographie choisie.

5 Au contraire des Nouvelles, les éditions des Caprices de Marianne ne manquent pas. Celle présentée par Frank Lestringant est cependant la bienvenue. Elle comprend une préface, des notes, un résumé de l'intrigue, l'historique de la représentation de la pièce, une chronologie (très fournie) de la vie de l'auteur, une notice sur le texte en deux parties («Sources et rapprochements»; «De la lecture à la scène: les deux versions des Caprices») et une bibliographie.

6 La préface situe l'œuvre dans un contexte biographique et esthétique propre à Musset et son époque. Elle s'arrête longuement sur le mot «caprices», à propos duquel Lestringant évoque non seulement la série de Goya ainsi nommée, mais aussi la psychologie des personnages, agissant souvent sur coup de tête, et le rythme de la pièce, marquée par des transitions plutôt brusques. Le thème du double, souvent traité à propos de Musset, est présenté non seulement par rapport au couple Cœlio-Octave, mais aussi en une vision de l'amour-amitié ambiguë. Cependant, c'est à Marianne-sa personnalité, son rôle dans l'intrigue et sa parole-que revient la partie la plus originale et la plus fructueuse de l'analyse des personnages. Félicitons Lestringant d'avoir rendu au personnage éponyme toute sa complexité, tout son intérêt, toute son importance; les pages qu'il lui a consacrées méritent d'être lues et relues: toute nouvelle analyse de la pièce, qu'elle se fonde sur elle ou s'en démarque, devra désormais en tenir compte.

7 Le dossier, placé après le texte, est aussi une source de renseignements et d'analyses intéresssante. On lira avec profit la notice pour bien comprendre ce que Musset doit à Shakespeare, par exemple, et distinguer ce qui sépare les deux versions du texte. L'évolution historique de la mise en scène constitue un élément important de l'histoire 
d'une pièce, mais elle est rarement présentée: nous pouvons la suivre -commentaires contemporains à l'appui, Lestringant rappelant que ce texte, d'abord destiné à la lecture, est ensuite passé sur scène. Il est à souhaiter que tous les éditeurs des pièces du répertoire nous fournissent des documents semblables. Ce dossier, avec les notes, le résumé et la bibliographie, rend le texte particulièrement accessible aux élèves et étudiants à qui on peut recommander cette édition avec la même confiance qu'aux chercheurs. 